\title{
Bromocriptine restores tolerance in estrogen-treated mice
}

\author{
Elena Peeva, ${ }^{1}$ Christine Grimaldi, ${ }^{2}$ Linda Spatz, ${ }^{3}$ and Betty Diamond ${ }^{1,2}$ \\ ${ }^{1}$ Department of Medicine, and \\ ${ }^{2}$ Department of Microbiology and Immunology, Albert Einstein College of Medicine, Bronx, New York, USA \\ ${ }^{3}$ Department of Microbiology and Immunology, City University of New York, New York, New York, USA \\ Address correspondence to: Betty Diamond, Department of Microbiology and Immunology, \\ Albert Einstein College of Medicine, 1300 Morris Park Avenue, Bronx, New York 10461, USA. \\ Phone: (718) 430-4081; Fax: (718) 430-8711; E-mail: diamond@aecom.yu.edu. \\ Received for publication May 24, 2000, and accepted in revised form October 16, 2000.
}

\begin{abstract}
Estrogen can modulate autoimmunity in certain models of systemic lupus erythematosus. Recently, we have shown that it can mediate survival and activation of anti-DNA B cells in a mouse transgenic for the heavy chain of a pathogenic anti-DNA antibody. To identify whether estrogen effects reflect increased prolactin secretion, we characterized B-cell autoreactivity in transgenic mice given both bromocriptine (an inhibitor of prolactin secretion) and estradiol. Treatment of mice with estradiol plus bromocriptine led to reduced titers of anti-DNA antibodies and diminished IgG deposition in kidneys compared with treatment with estradiol alone. However, mice treated with estradiol plus bromocriptine showed an expansion of transgene-expressing B cells and enhanced $\mathrm{Bcl}-2$ expression, similar to those of estradiol-treated mice. We identified anergic high-affinity anti-DNA B cells in mice treated with estradiol plus bromocriptine, and we showed by molecular analysis of anti-DNA hybridomas that their B cells derive from a naive repertoire. Thus, the estradiol-induced breakdown in B-cell tolerance can be abrogated by bromocriptine, which induces anergy in the high-affinity DNA-reactive $B$ cells. These studies demonstrate that some of the effects of estrogen on naive autoreactive $B$ cells require the presence of prolactin and, thus, suggest potential therapeutic interventions in lupus.

J. Clin. Invest. 106:1373-1379 (2000).
\end{abstract}

\section{Introduction}

Systemic lupus erythematosus (SLE) is an autoimmune disease primarily affecting young women. The peak incidence of disease occurs during childbearing age, with a female/male ratio of 9:1. This preponderance of lupus in women has been thought to reflect hormonal regulation of the immune system. Studies in patients with SLE and in animal models of this disease have suggested that a hyperestrogenic state may contribute to the disease process (1-7). These studies have demonstrated that estrogen exacerbates autoreactivity, but have not elucidated its mechanism of action at a cellular or molecular level. For example, it is not yet determined whether functional estrogen receptors are expressed in lymphocytes (8). Thus, it remains uncertain whether estrogen acts directly on lymphoid cells or whether the effects of estrogen on the immune system are indirect. Because estrogen is a physiological prolactin-stimulating agent (9), and because prolactin receptors have been demonstrated on both $\mathrm{T}$ and $\mathrm{B}$ lymphocytes (10-13), it is possible that the effects of estrogen are at least partially mediated through prolactin.

Prolactin is a peptide hormone that has been long known to affect mammary growth and development. There is increasing evidence that prolactin functions also as an immunostimulatory molecule and, therefore, has the potential to contribute to the pathogenesis of autoimmune diseases (14-21). An association between
SLE and elevated prolactin levels has been suggested (22-29); attempts to correlate prolactin levels with either global lupus activity (30-36) or specific organ involvement $(37,38)$, however, have yielded varying results. Small-scale clinical trials in SLE with bromocriptine, a drug that blocks prolactin secretion by the anterior pituitary, have suggested a beneficial effect in patients with mild and moderate disease activity (25, 39). Recent studies in female NZB/W F1 lupus-prone mice demonstrated that hyperprolactinemia leads to accelerated disease and early mortality $(40,41)$, whereas bromocriptine treatment improves survival (42).

To study the regulation of anti-double-stranded (ds) DNA B cells, our laboratory has generated BALB/c mice transgenic for $\gamma 2 b$ heavy chain of the pathogenic R4A anti-ds DNA antibody (43). In this model, the R4A heavy chain can associate with the endogenous light chain repertoire, such that some transgene-encoded antibodies bind DNA while others do not. Three distinct populations of anti-ds DNA B cells have been identified: (a) an ignorant or indifferent B-cell population that is not tolerized and produces nonpathogenic, low-affinity anti-ds DNA antibodies (44); (b) an anergic population that produces high-affinity anti-ds DNA antibodies that acquire high affinity for DNA by somatic mutation $(45,46)$; and (c) a deleted population of naive $B$ cells in which unmutated germline immunoglobulin genes encode high-affinity anti-DNA antibodies. These deleted cells have been identified in 
R4A, bcl-2 double transgenic mice (47). Recent studies have demonstrated that the deleted population of antiDNA B cells is rescued and activated by treatment with estrogen and that high serum titers of anti-DNA antibody are present in estrogen-treated transgenic mice (48). The objective of the current study was to investigate whether the effect of estrogen on autoreactive $\mathrm{B}$-cell survival and activation is prolactin mediated.

We, therefore, decided to study prolactin-mediated modulation of DNA-reactive B cells using bromocriptine as an inhibitor of prolactin secretion. The results from our studies demonstrate that activation, but not rescue of anti-DNA B cells, is mediated by prolactin.

\section{Methods}

Transgenic mice. $\mathrm{BALB} / \mathrm{c}$ mice transgenic for the $\gamma 2 \mathrm{~b}$ heavy chain of the pathogenic R4A anti-ds DNA antibody were bred at the animal facility of the Albert Einstein College of Medicine. Female mice, 10-16 weeks old, were used in these studies.

Estrogen treatment. The R4A transgenic mice were given subcutaneous implants of $17 \beta$-estradiol $\left(E_{2}\right)$ or placebo (Innovative Research of America, Medo, Ohio, USA), as described previously (48). The estradiol pellets have been demonstrated to release estradiol at a constant serum level of 75-100 pg/ml for 6-8 weeks.

Bromocriptine treatment. Bromocriptine (Sigma Chemical Co., St. Louis, Missouri, USA) at a dose of $400 \mu \mathrm{g}$ daily was injected intraperitoneally into mice with estradiol implants beginning 1 week after estradiol implantation for a total of 4 weeks. The dose of bromocriptine was chosen to effectively suppress serum prolactin levels to the level present in hypophysectomized animals (41). Mice were not treated with bromocriptine alone, as there could be no decrease in autoreactivity below baseline (untreated) levels.

ELISAs. Immulon-2 plates (Dynex Technologies, Chantilly, Virginia, USA) were coated with calf thymus ds DNA, dried overnight at $37^{\circ} \mathrm{C}$ and then blocked with $1 \%$ PBS-BSA for 90 minutes at $37^{\circ} \mathrm{C}$. The plates were incubated for 90 minutes at $37^{\circ} \mathrm{C}$ with supernatants normalized to $5 \mu \mathrm{g} / \mathrm{ml}$ or with serum diluted 1:500. Anti-ds DNA antibodies were detected with isotype-specific secondary antibodies coupled to alkaline phosphatase (Southern Biotechnology, Birmingham, Alabama, USA) diluted 1:1,000. The plates were developed with the substrate $p$-nitrophenylphosphate sodium (Sigma Chemi-

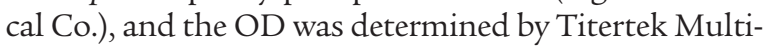
scan Plus ELISA reader (Eflab, Helsinki, Finland).

Flow cytometry. Splenocytes were isolated from placebo-, estradiol-, or estradiol plus bromocriptine-treated mice. Red blood cell lysis was performed by treatment with $0.17 \mathrm{M} \mathrm{NH}_{4} \mathrm{Cl}$ for 5 minutes at room temperature. Spleen cells were stained with FITC- or PE-conjugated antibodies specific for B220, or $\gamma 2 \mathrm{~b}$ (PharMingen, San Diego, California, USA), at $4^{\circ} \mathrm{C}$ for 30 minutes, washed, fixed with $2 \%$ paraformaldehyde and analyzed by flow cytometry (Becton Dickinson Immunocytometry Systems, Mountain View, California, USA).
To examine intracellular levels of Bcl-2, splenocytes were first stained with $\mathrm{Cy}$-Chrome-conjugated antibodies specific for CD19 (Caltag Laboratories, Burlingame, California, USA) and fixed with $1 \%$ paraformaldehyde. After fixation, the cells were incubated with $0.3 \%$ saponin (Sigma Chemical Co.) and rabbit anti-Bc1-2 IgG (Santa Cruz Biotechnology Inc., Santa Cruz, California, USA) on ice for 30 minutes. After washing with $0.03 \%$ saponin, the splenocytes were incubated with FITC-goat anti-rabbit IgG antibody (PharMingen) for 30 minutes, fixed with 1\% paraformaldehyde, and analyzed by FACScan flow cytometer (Becton Dickinson Immunocytometry Systems). The data was analyzed with Cell Quest software (Becton Dickinson Immunocytometry Systems).

ELISPOT assay. Splenocytes alone or stimulated with LPS $20 \mu \mathrm{g} / \mathrm{ml}$ (Sigma Chemical Co.) or anti-CD40 (20 $\mu \mathrm{g} / \mathrm{ml})$ (PharMingen) and IL-4 (300 U/106 cells) (PharMingen) were incubated in RPMI media containing $10 \%$ FCS at $37^{\circ} \mathrm{C}$. After 48 hours, splenocytes were washed and added to Immulon-2 plates coated with 50 $\mu \mathrm{l} /$ well of calf thymus ds DNA at a concentration of 100 $\mu \mathrm{g} / \mathrm{ml}$. After 4 hours of incubation, biotin-conjugated goat anti-mouse $\gamma 2 \mathrm{~b}$ (Southern Biotechnology) diluted 1:1,000 was added and plates were incubated overnight at $4{ }^{\circ} \mathrm{C}$. Plates were incubated with alkaline phosphatase-conjugated streptavidin (Southern Biotechnology) at a 1:1,000 dilution for an hour at room temperature. The plates were developed with 5-bromo-4-chloro-3 indolyl phosphate substrate (Sigma Chemical Co.) at room temperature for 2-4 hours. Spots were counted under a dissecting microscope.

Glomerular immunoglobulin deposition. Kidney sections were prepared as described previously (49). Formalinfixed, paraffin-embedded kidney sections were stained with biotinylated-anti-mouse IgG antibody and developed with the alkaline phosphatase $\mathrm{ABC}$ detection kit (Vector Laboratories, Burlingame, California, USA). IgG deposition assessment was based on the percent of IgG-stained glomeruli in 50 counted glomeruli. Kidneys with less than $25 \%$ stained glomeruli were graded as $+; 25-75 \%$, as ++ ; and more than $75 \%$, as +++ .

$B$-Cell hybridomas. Splenocytes were isolated from R4A transgenic $\mathrm{BALB} / \mathrm{c}$ mice treated with estradiol plus bromocriptine. Red blood cells were lysed, and isolated splenocytes were fused to NSO cells at 2:1 ratio using standard hybridoma methodology (50). The hybridomas were plated in 96-well U-bottom Costar plates (Corning, New York, USA) at $2 \times 10^{5}$ cells $/ \mathrm{ml}$ in HAT medium. Hybridoma supernatants were normalized for $\gamma 2 \mathrm{~b}$ concentration at $5 \mu \mathrm{g} / \mathrm{ml}$ and were screened for DNA binding by ELISA.

RNA dot blots. The anti-ds DNA antibody-producing hybridomas were screened for transgene expression by RNA dot blot, as described previously (45). The cells were lysed with lysis buffer: $2.5 \mathrm{M} \mathrm{KSCN}$ (Mallinckrodt Inc., Paris, Kentucky, USA), $2.5 \mathrm{mM}$ sodium citrate (J.T. Baker Inc., Phillipsburg, New Jersey, USA), and 50\% DMSO (Mallinckrodt Inc.). The lysates were transferred 
a

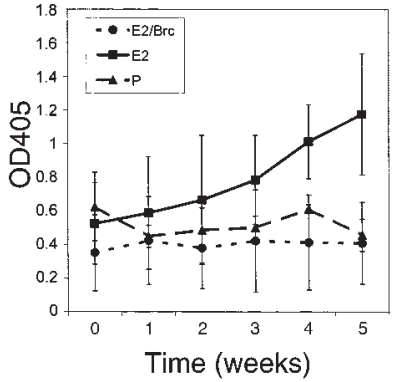

b

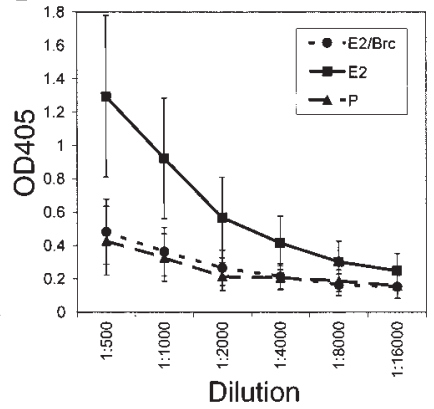

Figure 1

Serum titers of anti-ds DNA reactivity. Twenty-three BALB/c R4A transgenic mice were included in the experiment. Four mice were given subcutaneous implants of placebo $(P)$ pellets, and 19 were given estradiol (E2) implants. Bromocriptine (Brc) at a dose of $400 \mu \mathrm{g}$ daily was injected intraperitoneally in ten mice with $\mathrm{E} 2$ implants beginning 1 week after implantation and continuing for 4 weeks. Sera were collected before the implantation of the pellets and then weekly after implantation. All sera were assayed by ELISA for anti-DNA binding in the same assay. (a) Anti-DNA reactivity on serum diluted 1:500 was significantly higher in E2-treated mice than in E2 plus Brc-treated mice ( $P=0.01$ at the end of week 3 , and $P<0.01$ at weeks 4 and 5$)$. There was no significant difference in anti-DNA reactivity between placebo- and E2 plus Brc-treated mice. (b) Anti-DNA reactivity from serum obtained after 5 weeks of treatment was assayed at different dilutions. E2-treated mice demonstrated significantly higher titers at dilutions less than 1:1,000 $(P<0.01)$. The results are expressed as the mean absorbance at $405 \mathrm{~nm} \pm \mathrm{SD}$ (OD405).

to nitrocellulose and hybridized to a ${ }^{32}$ P-labeled 210-bp DNA fragment that detects all members of the $S 107 \mathrm{~V}_{\mathrm{H}}$ family. The $\mathrm{S} 107 \mathrm{~V}_{\mathrm{H}}-$ positive hybridomas were screened for expression of a VK1 light chain by RNA dot blot using a 230-bp probe for genes of the VK1 family (46).

Light chain gene usage. Light chains of R4A transgenicexpressing anti-ds DNA-secreting hybridomas were sequenced. RNA was extracted, and RT-PCR was performed using FR1 VK primers and a $\kappa$ constant region primer as described elsewhere (46). The PCR products were purified by QIAquick spin columns (QIAGEN Inc., Santa Clara, California, USA). $V$ gene sequences were determined using an ABI 377 automated sequencer (Perkin-Elmer, Applied Biosystems, Foster City, California, USA). Sequence analysis was performed with Genetics Comparison Group software (Madison, Wisconsin, USA).

Statistical analysis. Standard statistical tests (mean value, SD, Student's $t$ test) were performed for data analysis.

\section{Results}

Anti-ds DNA antibody production in placebo-, estradiol, and estradiol plus bromocriptine-treated mice. We have previously demonstrated that estrogen abrogates $B$-cell tolerance by enabling survival and

activation of DNA reactive B cells (48). The DNA-reactive population that is rescued is a population of naive $\mathrm{B}$ cells expressing unmutated light chains; this population is normally deleted when the transgene is expressed in a nonautoimmune mouse strain. To determine whether the estrogen effect is mediated through prolactin, we compared anti-DNA serum titers in $\mathrm{R} 4 \mathrm{~A}$ transgenic mice treated with placebo, estradiol, and estradiol plus bromocriptine, which suppresses prolactin secretion. Four female R4A- $\gamma 2 \mathrm{~b}$ transgenic $\mathrm{BALB} / \mathrm{c}$ mice were implanted with placebo pellets, whereas 19 were implanted with estradiol pellets. A week after implantation, ten of 19 estradiol-implanted mice were treated with bromocriptine for 4 weeks. Blood samples were collected on a weekly basis starting a day before implantation. Serum samples were analyzed for anti-DNA antibody production by ELISA. By the fourth and fifth week of treatment, the titers of anti-ds DNA antibodies increased significantly in estradiol-treated mice compared with both placeboand estradiol plus bromocriptine-treated mice (Figure 1). There was no significant difference in the serum anti-DNA titers between placebo- and estradiol plus bromocriptine-treated mice, demonstrating that bromocriptine can abrogate the estradiol induced activation of DNA-reactive B cells.

Glomerular IgG deposition was detected in kidneys of 12 of 17 estradiol-treated mice (+ deposits in three mice, ++ in seven mice, and +++ in two mice), which was consistent with earlier findings that increased levels of estradiol lead to secretion of potentially pathogenic, high-affinity anti-ds DNA B cells (48). Glomerular deposits were found in only two of 18 estradiol plus bromocriptine-treated mice (+ deposits only) and in none of five placebo-treated mice (Figure 2). These findings were consistent with the previous observation that unmanipulated $\mathrm{R} 4 \mathrm{~A}$ transgenic $\mathrm{BALB} / \mathrm{c}$ mice effectively regulate the production of anti-ds DNA antibodies (43). Furthermore, these data demonstrate that

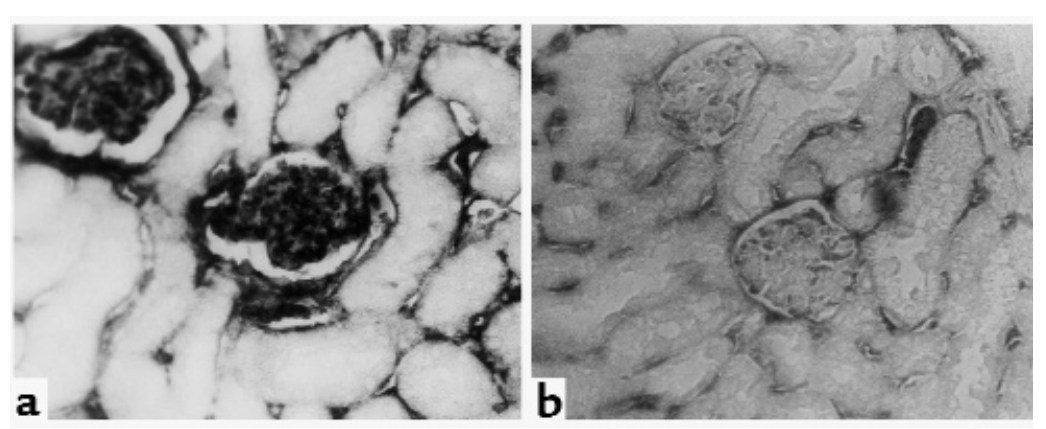

Figure 2

Immunohistochemistry of kidney sections. Five placebo-treated, 17 E2-treated, and 18 E2 plus Brc-treated mice were sacrificed 5 weeks after implantation. The kidneys immunostained for IgG deposition were read and graded by a blinded observer. IgG deposits were found in 12 E2-treated mice (+ deposits in three mice, ++ in seven mice, and +++ in two mice), in two of E2 plus Brc-treated mice (+ deposits only), and in none of placebo-treated mice. (a) A representative section from a mouse treated with E2, which developed glomerular deposits. (b) A representative section from a mouse treated with E2 plus Brc. $\times 40$. 


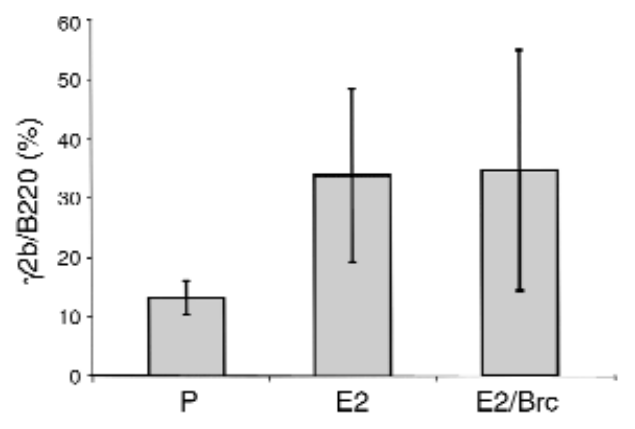

Figure 3

Analysis of peripheral lymphocytes by flow cytometry. Splenocytes were isolated from four placebo-treated, six E2-treated, and six E2 plus Brc-treated mice 5 weeks after pellet implantation. Data are presented as the mean \pm SD of transgene-positive $B$ cells. A higher percentage of $B$ cells express $\gamma 2 b$ in E2-treated and E2 plus Brc-treated mice than in placebo-treated mice $(P=0.01$ and $P=0.04$, respectively).

bromocriptine can block the increase in anti-ds DNA titer and associated glomerular immunoglobulin deposition that occurs with estradiol treatment.

Peripheral B-cell analysis. In the R4A transgenic mouse model, essentially all $\gamma 2 \mathrm{~b}$ B cells express the transgene (45, 46), and estradiol has been demonstrated to cause expansion of the transgene-expressing B-cell population (48). As with estradiol-treated R4A $\gamma 2 \mathrm{~B}$ mice, there was a significant increase in the percentage of transgenic $B$ cells in estradiol plus bromocriptine-treated mice (Figure 3).

Increased expression of the anti-apoptotic gene bcl-2 in $\mathrm{B}$ cells has been detected in estradiol-treated R4A transgenic mice and is presumed to help mediate the survival of autoreactive B cells (48). We demonstrated by flow cytometry an increase in $\mathrm{Bcl}-2$ expression in $\mathrm{B}$ cells not only in estradiol-treated, but also in estradiol plus bromocriptine-treated mice compared with placebotreated mice. There was no significant difference in Bcl2 expression between estradiol-treated and estradiol plus bromocriptine-treated mice (Figure 4). These results demonstrate that bromocriptine blocks neither the expansion of $\gamma 2 \mathrm{~b} B$ cells nor the increased expression of anti-apoptotic molecules mediated by estradiol.

Response to mitogenic stimulation. Because estradioltreated and estradiol plus bromocriptine-treated mice had equivalent numbers of $\gamma 2 \mathrm{~b} B$ cells, but estradiol plus bromocriptine-treated mice had lower titers of anti-DNA antibody, we reasoned that there might be a population of resting or anergic anti-DNA B cells present in estradiol plus bromocriptine-treated mice. There were more DNA-reactive B cells that spontaneously secreted antibody in estradiol-treated than in estradiol plus bromocriptine-treated mice without mitogenic stimulation (Figure 5). Anti-DNA-secreting $B$ cells were induced with LPS stimulation in all mice, consistent with the presence of either resting or anergic anti-DNA B cells. B cells from estradiol-treated mice were also activated to secrete anti-DNA antibodies by anti-CD40 plus IL-4, whereas the B cells from estradiol plus bromocriptine-treated mice did not respond to these activators (Figure 5), demonstrating that the anti-DNA B cells in estradiol plus bromocriptine-treated mice are anergic.

$B$-cell hybridomas from estradiol plus bromocriptine-treated mice. To characterize the DNA-reactive $\mathrm{B}$ cells present in estradiol plus bromocriptine-treated mice, we generated hybridomas from unstimulated and LPS-stimulated B cells. Approximately 450 wells from three fusions produced hybridomas; 40 of 250 LPS and 12 of 200 non-LPS-stimulated B-cell hybridomas produced antiDNA antibody. All DNA-reactive cell lines expressed the $\gamma 2 \mathrm{~b}$ transgene. The supernatants of transgene-expressing clones were normalized to a $\gamma 2 \mathrm{~b}$ concentration of $5 \mu \mathrm{g} / \mathrm{ml}$. Sixteen hybridomas were selected for further analysis. Six of seven hybridomas derived from unstimulated $B$ cells produced low-affinity anti-DNA antibody (Figure 6). These hybridomas used a variety of non-Vk1 light chains, including Vk4, Vk8, and Vk21. One light chain displayed evidence of somatic mutation, but it is not known whether the mutations were critical for generation of anti-DNA specificity. In contrast, all the hybridomas generated from LPS-stimulated $B$ cells produced high-affinity anti-DNA antibodies; all but one used a Vk1 light chain; all expressed a germline, unmutated light chain gene (Figure 6) (Genbank accession numbers: M15566, M28131, M15567, U88687, X59193, L17135, K02159, and AF178630). Thus, the B cells from estradiol plus bromocriptine-treated mice that were immortalized following LPS stimulation were part of a naive $B$-cell repertoire and were derived from the population of $B$ cells that has previously been shown to be rescued from deletion by estrogen, but remained tolerized in the periphery.

\section{Discussion}

Clinical data and studies in animal models of lupus have implicated estrogen as a possible exacerbating factor in SLE. Recent studies have shown that estrogen a

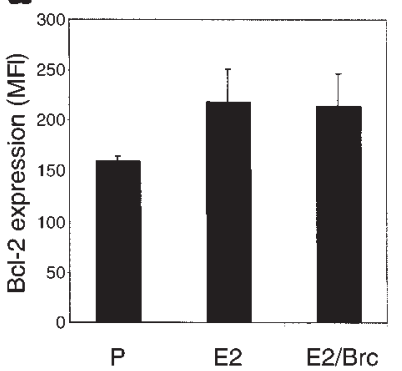

b

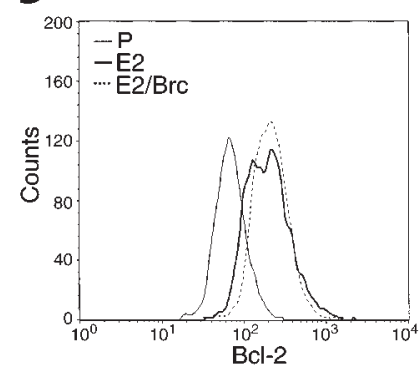

\section{Figure 4}

Flow cytometric analysis of $\mathrm{Bcl}-2$ expression in $\mathrm{B}$ cells. Splenocytes from five placebo-treated, six E2-treated, and six E2 plus Brc-treated mice were isolated 5 weeks after pellet implantation, labeled with antibodies against the CD19 surface marker and then stained for intracellular $\mathrm{Bcl}-2$. (a) The $\mathrm{Bcl}-2$ expression denoted by mean fluorescence intensity (MFI) was significantly higher in E2-treated and E2 plus Brc-treated than in placebo-treated mice ( $P<0.01$ and $P=0.03$, respectively). (b) Representative histograms of $\mathrm{Bcl}-2$ in placebo-treated (thin line), E2-treated (thick line), and E2 plus Brc-treated (dotted line) mice. 


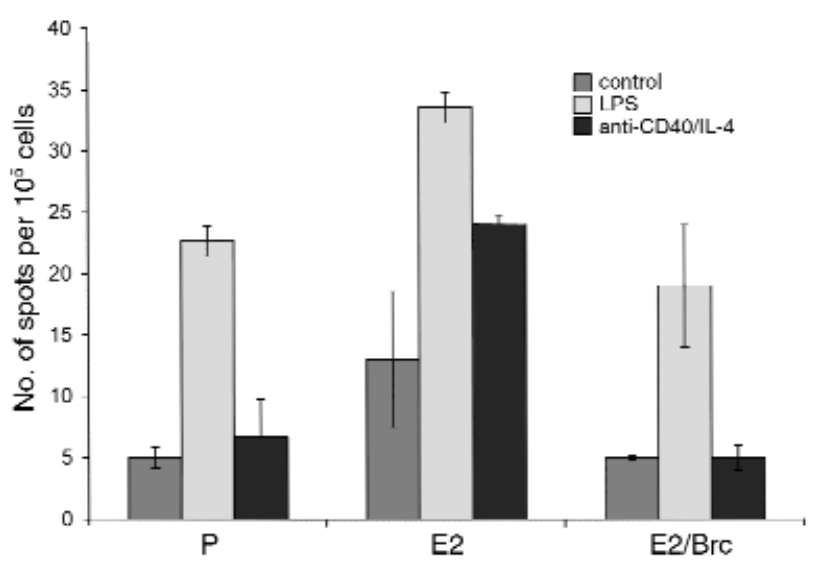

treatment can induce anti-ds DNA antibody production in non-autoimmune C57BL/6 and anti-DNA transgenic BALB/c mice $(7,48)$, further supporting the potential of estrogen to contribute to the development of SLE. Our laboratory has shown that estradiol blocks deletion of naive autoreactive $\mathrm{B}$ cells that arise in the bone marrow. However, it remains unclear whether the immunostimulatory effects of estrogen are direct or are mediated through induction of other factors. Because estrogen increases prolactin secretion $(51,52)$ and B cells express prolactin receptors $(10,13)$, it is possible that the effect of estrogen on lymphoid cells is, at least in part, mediated through prolactin. In this model, estrogen would increase prolactin levels and prolactin might then act directly and independently on lymphoid cells. If this model is correct, then bromocriptine, which blocks prolactin secretion, should reverse the effects of estradiol on B cells in vivo.

The R4A- $\gamma 2 \mathrm{~b}$ transgenic mouse model is well characterized and offers an excellent system in which to study B-cell fate. Using this model, we have shown that estradiol can rescue naive high-affinity antiDNA B cells and induce pathogenic anti-ds DNA antibody production (48). We used this model to

\section{Figure 5}

Enumeration of naive and stimulated anti-DNA-secreting B cells. Splenocytes from five placebo-treated, six E2-treated, and five E2 plus Brc-treated mice were isolated 5 weeks after pellet implantation, and incubated alone or with LPS, or anti-CD $40 / \mathrm{IL}-4$ at $37^{\circ} \mathrm{C}$ for 48 hours. The DNAreactive $B$ cells from each group were enumerated by ELISPOT assay at $10^{5}$ cells. There was a significantly higher number of spontaneously secreting DNA-reactive B cells in E2-treated mice than in placebo-treated and E2 plus Brc-treated mice $(P<0.01)$. LPS induced a significant increase in anti-DNA-secreting B cells in E2-treated, E2 plus Brc-treated, and placebo-treated mice. There was a response to anti-CD40/IL-4 only in E2-treated mice $(P<0.01)$; whereas E2 plus Brc-treated mice did not demonstrate a significant increase in anti-ds DNA secretion after incubation with anti-CD40/IL-4. Data are presented as the mean \pm SD. Similar results were obtained in two separate experiments. investigate whether the immunostimulatory effects of estrogen are prolactin mediated, using bromocriptine to block prolactin secretion.

Bromocriptine is a dopamine agonist that acts as a prolactin-release inhibitor, and its major immunosuppressive activity is thought to be dependent on its hypoprolactinemic effect (53). The data reported here provide evidence that bromocriptine can abrogate the activation of autoreactive $\mathrm{B}$ cells and the induction of glomerular deposition mediated by estradiol in R $4 A-\gamma 2 b$ transgenic mice.

Bromocriptine treatment did not, however, reverse all the effects of estradiol and did not lead to restoration of the phenotype of the untreated mice. The expansion of transgene-expressing B cells that is found in estradiol-treated mice was also present in estradiol plus bromocriptine-treated mice, demonstrating that this effect is not mediated through prolactin. Although both untreated and estradiol plus bromocriptine-treated mice maintain tolerance, and both possess populations of indifferent and anergic autoreactive $B$ cells, the anti-DNA B cells in estradiol plus bromocriptine-treated mice differed from those in untreated mice. In untreated mice, we have shown that there is a popula-

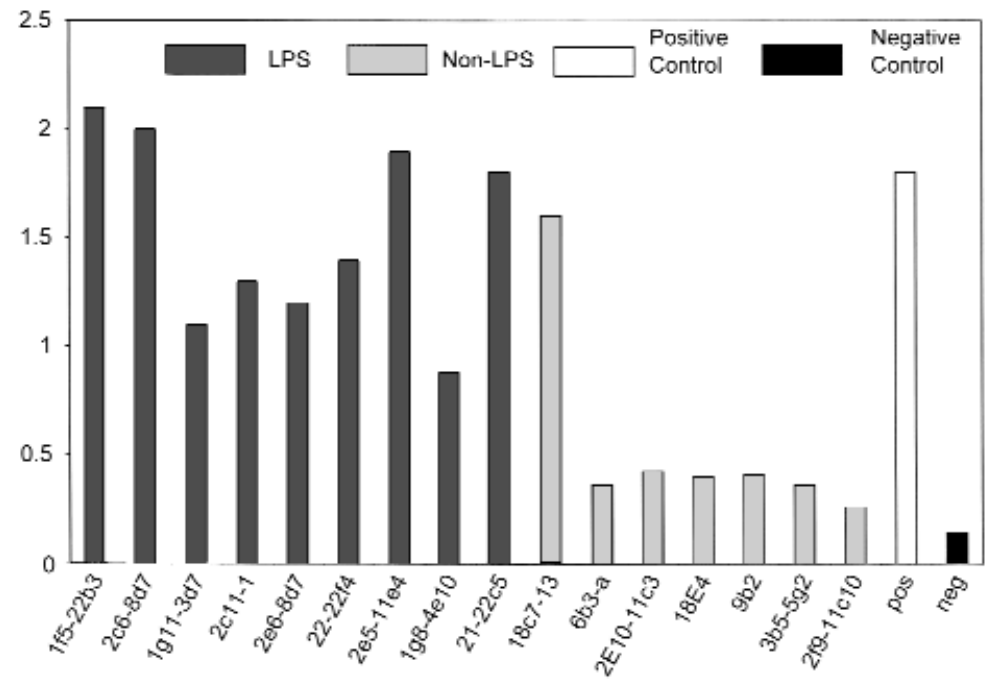

\section{Figure 6}

DNA-reactive hybridomas. Hybridomas were generated with the NSO fusion partner and either nonstimulated or LPS-stimulated B cells from R4A transgenic mice treated with E2 plus Brc. Supernatants from DNA-reactive R4A-positive clones were normalized to a $\gamma 2 \mathrm{~b}$ concentration of $5 \mu \mathrm{g} / \mathrm{ml}$ and assayed for binding to calf thymus ds DNA by ELISA. R4A- $\gamma 2 b$ antibody and irrelevant $\gamma 2 b$ were used as positive and negative controls, respectively. Dark gray bars, LPS stimulated clones; light gray bars, non-LPS-stimulated clones. 
tion of anergic B cells that is immortalized by cell fusion only after LPS stimulation, displays somatically mutated light chains, and appears to have acquired high affinity for DNA as a consequence of somatic mutation of the light chain. This population shows evidence, therefore, of having been activated in vivo. In estradiol plus bromocriptine-treated mice, the anergic population is a naive autoreactive population derived from a B-cell population that is normally deleted. There is no evidence of activation of this B-cell population in estradiol plus bromocriptine-treated mice. Most notably, there is no evidence for activation of lowaffinity anti-DNA B cells such as is present before anergy induction in untreated mice.

In summary, there are two features of estradiol plus bromocriptine-treated mice that differ from those of untreated mice. The first observation is that there is an expansion of transgene-expressing $\gamma 2 \mathrm{~b}$-producing $\mathrm{B}$ cells. Even in the presence of bromocriptine, estradiol continues to lead to an augmentation of transgene expressing $\mathrm{B}$ cells.

It might be argued that during the week of exposure to estradiol before initiation of bromocriptine treatment, there was an opportunity for survival of autoreactive transgene-expressing $\mathrm{B}$ cells and that the enhanced number of transgene-expressing $B$ cells reflects the action of estradiol during the week of estradiol treatment before treatment with bromocriptine was begun. We believe this explanation is unlikely because the expansion of $\gamma 2 \mathrm{~b} \mathrm{~B}$ cells is identical in estradiol-treated and estradiol plus bromocriptine-treated mice. Furthermore, the percent of hybridomas making anti-DNA antibodies from estradiol and estradiol plus bromocriptine-treated mice is also the same, $10-15 \%$. If high-affinity anti-DNA B cells were rescued for only 1 week, and during the subsequent 4 weeks all newly arising high-affinity anti-DNA $\mathrm{B}$ cells were deleted, the presence of such B cells after 5 weeks would be diminished in mice receiving bromocriptine.

The second observation is that there is survival of naive, high-affinity anti-DNA B cells but little, if any, evidence for activation of this population. There is only one light chain that displays any mutation. Moreover, in the presence of bromocriptine, or in absence of prolactin, the high-affinity anti-DNA B cells do not secrete anti-DNA antibody spontaneously or in the presence of anti-CD40 and IL-4, although they do secrete antibody when stimulated with LPS. These cells appear to be anergic, or unusually resistant to activation. Thus, in estradiol plus bromocriptine-treated mice, there is rescue of autoreactive $B$ cells consistent with the upregulation of Bcl-2, but the cells are present in a state that is nonresponsive to physiological activation signals.

There are experimental data from in vitro cultures of either $\mathrm{T}$ or $\mathrm{B}$ cells with mitogen, demonstrating that bromocriptine can block mitogenic activation of both $T$ and $B$ cells $(54,55)$ and suggesting that bromocriptine may directly affect lymphoid cells. More recent studies suggest that bromocriptine acts on the immune system exclusively by decreasing titers of prolactin (53). We cannot know in our study whether the effect of bromocriptine is exclusively mediated through a decrease in prolactin rather than a direct effect on lymphoid cells. Preliminary studies, however, suggest than elevations of prolactin can break tolerance. We do not yet know whether any of the mechanism(s) of breakdown in tolerance is similar to the mechanisms operative in estrogen-induced autoimmunity. We have not yet determined why anergy would develop in the absence of prolactin. It is possible that prolactin is necessary to activate the $\mathrm{B}$ cell. Alternatively, it may be that the activation of autoreactive B cells in this model is T-cell dependent. In the absence of prolactin, $T$ cells may have a diminished ability to provide help to autoreactive B cells. Autoreactive B cells encountering antigen in the absence of T-cell help undergo anergy induction. We favor this hypothesis.

These data confirm, in a novel murine SLE model, that bromocriptine can reduce anti-DNA antibody titers. This study demonstrates that survival of autoreactive $B$ cells can be uncoupled from activation of those B cells by manipulating hormone concentrations, and it begins to dissect the role of different hormones in the survival and activation of autoreactive B cells.

\section{Acknowledgments}

We acknowledge Susan Buhl, Xian Chen, and Ila Joshi for technical support, and Sylvia Jones for expert secretarial assistance. This work was supported by grants from the National Institute of Allergy and Infectious Diseases and the National Institute of Arthritis and Musculoskeletal and Skin Diseases. Elena Peeva is a Fellow of the SLE Foundation. Christine Grimaldi is a Fellow of the Irvington Institute for Immunological Research.

1. Ansar Ahmed, S., Penhale, W.J., and Talal, N. 1985. Sex hormones, immune responses, and autoimmune diseases. Am. J. Pathol. 121:531-551.

2. Grossman, C.J., Roselle, G.A., and Mendenhall, C.L. 1991. Sex steroid regulation of autoimmunity. J. Steroid Biochem. Mol. Biol. 40:649-659.

3. Lahita, R.G. 1985. Sex steroids and the rheumatic diseases. Arthritis Rheum. 28:121-126.

4. Homo-Delarche, F., et al. 1991. Sex steroids, glucocorticoids, stress and autoimmunity. Steroid Biochem. Mol.Biol. 40:619-637.

5. Paavonen, T. 1991. Hormonal regulation of immune responses. Ann. Med. 26:255-258.

6. Ansar Ahmed, S., and Talal, N. 1989. Sex hormones and autoimmune rheumatic disorders. Scand. J. Rheumatol. 18:69-76.

7. Verthelyi, D., and Ansar Ahmed, S. 1994. 17ß-Estradiol, but not 5 $\alpha$-Dihydrotestosterone, augments antibodies to double-stranded DNA in nonautoimmune C57BL/6J mice. Endocrinology. 135:2615-2622.

8. King, A., Gardner, L., and Loke, Y.W. 1996. Evaluation of estrogen and progesterone receptor expression in uterine mucosal lymphocytes. Hum. Reprod. 11:1079-1082.

9. Franks, S. 1983. Regulation of prolactin secretion by estrogens: physiological and pathological significance. Clin. Sci. 65:457-462.

10. Russel, D.H., et al. 1984. Prolactin receptors on human lymphocytes and their regulation by cyclosporine. Biochem. Biophys. Res. Commun. 121:899-906.

11. Matera, L., Muccioli, G., Cesano, A., Bellussi, G., and Genazzani, V. 1988. Prolactin receptors on large granular lymphocytes: dual regulation by cyclosporin A. Brain Behav. Immun. 2:1-10.

12. Gagnerault, M.C., Touraine, P., Savino, W., Kelly, P.A., and Dardenne, M. 1993. Expression of prolactin receptors in murine lymphoid cells in normal and autoimmune situations. J. Immunol. 150:5673-5681.

13. Pellegrini, I., Lebrun, J., Ali, S., and Kelly, P.A. 1992. Expression of pro- 
lactin and its receptor in human lymphoid cells. Mol. Endocrinol. 6:1023-1031.

14. Berczi, I. 1993. The role of prolactin in the pathogenesis of autoimmune disease. Endocr. Pathol. 4:178-195.

15. Berczi, I. 1993. Prolactin, pregnancy and autoimmune disease. J. Rheumatol. 20:1095 - 1100 .

16. Draca, S. 1995. Prolactin as an immunoreactive agent. Immunol. Cell. Biol. 73:481-483.

17. Matera, L. 1996. Endocrine, paracrine and autocrine actions of prolactin on immune cells. Life Sci. 59:599-614.

18. Berczi, I., Chalmers, I.M., Nagy, E., and Warrington, R.J. 1996. The immune effects of neuropeptides. Baillieres Clin. Rheumatol. 10:227-257.

19. Yu-Lee, L.Y. 1997. Molecular actions of prolactin in the immune system. Proc. Soc. Exp. Biol. Med. 215:1-18.

20. Berczi, I. 1997. Pituitary hormones and immune function. Acta Paediatr. Suppl. 423:70-75.

21. Jara, L.J., et al. 1991. Prolactin, immunoregulation, and autoimmune diseases. Semin. Arthritis Rheum. 20:273-284.

22. McMurray, R.W. 1996. Prolactin and systemic lupus erythematosus. Ann. Med. Interne (Paris). 147:253-258.

23. Lavalle, C.E., et al. 1993. Prolactin and gonadal hormones: a key relationship that may have clinical, monitoring and therapeutic implications in systemic lupus erythematosus. Lupus. 2:71-75.

24. Walker, S.E., et al. 1998. Effects of prolactin in stimulating disease activity in systemic lupus erythematosus. Ann. NY Acad. Sci. 840:762-772.

25. McMurray, R.W., Weidensaul, D., Allen, S.H., and Walker, S.E. 1995. Efficacy of bromocriptine in an open label therapeutic trial for SLE. $J$. Rheumatol. 22:2084-2091.

26. Walker, S.E., Allen, S.H., Hoffman, R.W., and McMurray, R.W. 1995. Prolactin: a stimulator of disease activity in SLE. Lupus. 4:3-9.

27. Allen, S.H., et al. 1996. Prolactin levels and antinuclear antibody profiles in women tested for connective tissue disease. Lupus. 5:30-37.

28. Jara, L.J., et al. 1992. Hyperprolactinemia in SLE: association with disease. Am. J. Med. Sci. 303:222-226.

29. Lavalle, C., et al. 1987. Correlation study between prolactin and androgens in male patients with SLE. J. Rheumatol. 14:268-272

30. Folomeev, M., et al. 1990. Prolactin levels in men with SLE and RA. $J$ Rheumatol. 17:1569-1570.

31. Jimena, P., et al. 1998. Prolactin levels in patients with SLE: a case controlled study. Lupus. 7:383-386.

32. Blanco-Favela, F., Quintal-Alvarez, G., and Leanos-Miranda, A. 1999 Association between prolactin and disease activity in systemic lupus erythematosus. Influence of statistical power. J. Rheumatol. 26:55-59.

33. Jara-Quezada, L., Graef, A., and Lavalle, C. 1991. Prolactin and gonadal hormones during pregnancy in systemic lupus erythematosus. J. Rheumatol. 18:349-353.

34. Neidhart, M. 1996. Elevated serum prolactin or elevated prolactin/cortisol ratio are associated with autoimmune processes in systemic lupus erythematosus and other connective tissue diseases. Br. J. Rheumatol. 23:476-481.

35. Munoz, J.A., Gil, A., Lopez-Dupla, J.M., Vazquez, J.J., and GonzalezGansedo, P. 1994. Sex hormones in chronic systemic lupus erythematosus. Correlation with clinical and biological parameters. Ann. Med. Interne (Paris). 145:459-463.

36. Ostendorf, B., et al. 1996. Hyperprolactinemia in systemic lupus erythe- matosus. Scand. J. Rheumatol. 25:97-102.

37. El-Garf, A., Salah, S., Shaarawy, M., Zaki, S. and Anwer, S. 1996. Prolactin hormone in juvenile systemic lupus erythematosus: a possible relationship to disease activity and CNS manifestations. J. Rheumatol. 23:374-377.

38. Miranda, J.M., et al. 1998. Clinical significance of serum and urine prolactin levels in lupus glomerulonephritis. Lupus. 7:387-391.

39. Alvarez-Nemegyei, J., et al. 1998. Bromocriptine in systemic lupus erythematosus: a double-blind, randomized, placebo-controlled study. Lupus. 7:414-419.

40. Walker, S.E., McMurray, R.W., Besch-Williford, C.L., and Keisler, D.H. 1992. Premature death with bladder outlet obstruction and hyperprolactinemia in NZB/NZW mice treated with ethynil estradiol and $17 \beta$ estradiol. Arthritis Rheum. 35:1387-1392.

41. McMurray, R., Keisler, D., Kanuckel, K., Izui, S., and Walker, S. 1991. Prolactin influences autoimmune disease activity in the female NZB/W mouse. J. Immunol. 147:3780-3787.

42. Elbourne, K.B., Keisler, D., and McMurray, R.W. 1998. Differential effects of estrogen and prolactin on autoimmune disease in the NZB/NZW F1 mouse model of SLE. Lupus. 7:420-427.

43. Offen, D., Spatz, L., Escowitz, H., Factor, S., and Diamond, B. 1992. Induction of tolerance to an IgG autoantibody. Proc. Natl. Acad. Sci. USA. 89:8332-8336.

44. Bynoe, M.S., Spatz, L., and Diamond, B. 1999. Characterization of antiDNA B cells that escape negative selection. Eur. J. Immunol. 29:1304-1313.

45. Iliev, A., Spatz, L., Ray, S., and Diamond, B. 1994. Lack of allelic exclusion permits autoreactive B cells to escape deletion. J. Immunol. 153:3551-3556.

46. Spatz, L., et al. 1997. Light chain usage in anti ds DNA B cell subsets: role in cell fate determination. J. Exp. Med. 185:1317-1326.

47. Kuo, P., Bynoe, M.S., Wang, C., and Diamond, B. 1999. Bcl-2 leads to expression of anti-DNA B cells but no nephritis: a model for a clinical subset. Eur. J. Immunol. 29:3168-3178.

48. Bynoe, M.S., Grimaldi, C.M., and Diamond, B. 2000. Estrogen upregulates Bcl-2 and blocks tolerance induction of naïve B cells. Proc. Natl. Acad. Sci. USA. 97:2703-2708.

49. Gaynor, B., Putterman, C., Valadon, P., Spatz, L., Scharff, M.D., and Diamond, B. 1997. Peptide inhibition of glomerular deposition of an antiDNA antibody. Proc. Natl. Acad. Sci. USA. 94:1955-1960.

50. Fazekas de St. Groth, B., and Scheidegger, D. 1980. Production of monoclonal antibodies: strategy and tactics. J. Immunol. Methods. 35:1-21.

51. Fink, G. 1988. Estrogen and progesterone interactions in the control of gonadotropin and prolactin secretion. J. Steroid Biochem. 30:169-178.

52. Gunes, H., Zawilla, S., and Mastro, A.M. 1997. Prolactin receptor expression by splenocytes from rats in various hormonal states. Cell Prolif. 30:127-137.

53. Neidhart, M. 1997. Bromocriptine has little effect on murine lymphocytes, the immunomodulatory effect being mediated by suppression of prolactin secretion. Biomed. Pharmacother. 51:118-125.

54. Morikawa, K., Oseko, F., and Morikawa, S. 1993. Immunosuppressive property of bromocriptine on human B lymphocyte function in vitro. Clin. Exp. Immunol. 93:200-205.

55. Morikawa, K., Oseko, F., and Morikawa, S. 1994. Immunosuppressive activity of bromocriptine on human Tlymphocyte function in vitro. Clin. Exp. Immunol. 95:514-518 